Review

\title{
Índices e Metodologias de Monitoramento de Secas: Uma Revisão
}

\author{
Suellen Teixeira Nobre Gonçalves ${ }^{1,2}$ (D), Francisco das Chagas Vasconcelos Junior ${ }^{1}$ (D), \\ Meiry Sayuri Sakamoto ${ }^{1}$ (D), Cleiton da Silva Silveira ${ }^{3}$ (D), \\ Eduardo Sávio Passos Rodrigues Martins ${ }^{1}$ \\ ${ }^{1}$ Fundação Cearense de Meteorologia e Recursos Hídricos, Fortaleza, CE, Brasil. \\ ${ }^{2}$ Mestrado Profissional em Climatologia e Aplicações nos Países da CPLP e África, Universidade \\ Estadual do Ceará, Fortaleza, CE, Brasil. \\ ${ }^{3}$ Universidade Federal do Ceará, Fortaleza, CE, Brasil.
}

Recebido em: 5 de Fevereiro de 2021 - Aceito em: 23 de Abril de 2021

\begin{abstract}
Resumo
O presente artigo faz uma revisão bibliográfica e aborda os principais índices utilizados no monitoramento e análise de secas. Além disso, o texto ainda discorre sobre as metodologias empregadas mundialmente no monitoramento e previsão desses eventos. As secas ocorrem quando existe um déficit de precipitação comparado à média histórica da região. Elas podem ser diagnosticadas por meio de índices que identificam os períodos de escassez ou de disponibilidade hídrica através de equações. Dessa forma, é possível determinar a intensidade, frequência e duração dos eventos de seca. Nesse âmbito, alguns países implementaram seus próprios sistemas de monitoramento e alerta precoce das secas como o Monitor de Secas dos Estados Unidos, o Monitor de Secas da Europa e o Monitor de Secas do Brasil. Onde estes, utilizam de forma conjunta ou isolada as informações provenientes dos índices, a fim de identificar e caracterizar os eventos de seca. Desse modo, pode haver um melhor planejamento das instituições responsáveis, adoção de planos emergenciais e mitigação de impactos.
\end{abstract}

Palavras-chave: precipitação, recursos hídricos, monitor de secas.

\section{Indices and Methodologies for Monitoring Droughts: A Review}

\begin{abstract}
The present work is a bibliographic review and addresses the main indexes used in the monitoring and analysis of droughts. In addition, the text also discusses the methodologies utilized worldwide in monitoring and forecasting these events. Droughts occur when there is a rainfall deficit compared to the region's historical average. They can be diagnosed by means of indices that identify periods of scarcity or availability hydric through equations. In this way, it is possible to determine the intensity, frequency, and duration of drought events. In this context, some countries have implemented their own drought monitoring and early warning systems such as the United States Drought Monitor, Europe's Drought Monitor and Brazil's Drought Monitor. Where they use information from indexes together or in isolation, in order to identify and characterize drought events. Thus, there can be better planning by the responsible institutions, adoption of emergency plans and mitigation of impacts.
\end{abstract}

Keywords: precipitation, water resources, drought monitor.

\section{Introdução}

As secas são fenômenos naturais que podem ocorrer em praticamente todas as zonas climáticas e não possuem início definido. Os períodos de seca estão relacionados com a redução da quantidade de precipitação recebida durante um longo espaço de tempo, causando grandes impactos para a humanidade e o meio ambiente (Mishra e Singh, 2010).

A compreensão das características de um evento de seca (frequência, intensidade, duração e extensão de área) requer uma ampla informação atual e histórica das con-

Autor de correspondência: Suellen Teixeira Nobre Gonçalves, suellen.nobre@gmail.com. 
dições meteorológicas e hidrológicas de uma determinada região. Esta percepção, se faz necessária para identificar as áreas vulneráveis a esse evento, reconhecer as condições de seca emergente e antecipar informações sobre o estado hídrico das regiões (Pontes Filho et al., 2019; Doesken et al., 1991).

As secas podem ser classificadas em quatro categorias, que correspondem ao tipo de impacto ocasionado, sendo elas: meteorológicas, agrícolas, hidrológicas e socioeconômicas. A seca meteorológica advém de uma redução significativa na precipitação, associada a um aumento expressivo da evapotranspiração, quando comparada com a média histórica de uma área. Seus impactos abrangem o sistema hidrológico e a utilização desses recursos (Pontes Filho et al., 2019; Pessini, 2017; Van Loo, 2015; Farajzadeh et al., 2009).

A seca agrícola surge quando o déficit de precipitação e de água no solo atinge a agricultura, afetando o plantio e a colheita. Nesse tipo de seca há uma redução da umidade do solo associada a elevadas perdas evaporativas, o que prejudica o crescimento e o desenvolvimento das culturas (Mishra e Singh, 2010; Farajzadeh et al., 2009; Kentayeshe e Dracup, 2002).

Já seca hidrológica descreve um período com redução significativa dos níveis médios dos recursos hídricos superficiais e subterrâneos. A ocorrência desse evento está diretamente ligada à longos períodos de seca meteorológica, pois a escassez de precipitação se propaga através do sistema hidrológico, causando distúrbios em diferentes segmentos da sociedade. O resultado desse tipo de seca é o racionamento, ou colapso, nos sistemas de abastecimento hídrico das cidades ou das áreas de irrigação (Pessini, 2017; Van Loo, 2015; Mishra e Singh, 2010; Farajzadeh et al., 2009).

As principais medidas adotadas na busca de soluções para esta problemática têm sido a construção de reservatórios, perfuração de poços, implantação de sistemas de irrigação e transposição de água. Essas ações têm por finalidade melhorar a garantia de acesso à água. A operação de reservatórios representa um método de tomada de decisão que conta com a participação de agentes sociais, políticos e econômicos e apresenta-se como uma fase relevante para aumentar a eficiência do gerenciamento dos recursos hídricos (Medeiros et al., 2016; Campos, 2006; Solon et al., 2001).

A partir da combinação das três secas mencionadas anteriormente, têm-se a seca socioeconômica, a qual se relaciona com a oferta e demanda por algum bem. A oferta de diversos recursos econômicos e bens, como água, alimentos e energia, dependem do clima. Devido à ocorrência de eventos de seca, o abastecimento de água se torna insuficiente para atender as necessidades humanas e ambientais (Pessini, 2017; Ferreira et al., 2015; Van Loo, 2015; Mishra e Singh, 2001; Farajzadeh et al., 2009).
O processo de adaptação à escassez hídrica requer o monitoramento da seca, que pode ser realizado a partir de índices, que tem por finalidade medir a intensidade, duração e frequência desses eventos. As informações fornecidas pelos índices são úteis para planejar e desenvolver ferramentas de apoio à decisão. Estas ferramentas podem ser utilizadas em políticas estaduais e federais como parâmetros para gerenciar os riscos em períodos de ocorrência ou recorrência de secas. Dessa forma, pode haver a adoção ou suspensão de ações emergenciais de convívio com a seca nos diversos setores da sociedade (Pontes Filho et al., 2019; Svoboda e Fuchs, 2016; Brain e Brunini, 2007).

Nesse contexto, foram desenvolvidos diversos sistemas de monitoramento e previsão das secas em algumas regiões do planeta, as quais incluem: Estados Unidos, Brasil, Canadá, Índia, México, África do Sul, Filipinas, Hungria, Romênia, China e Austrália. Estes utilizam de forma conjunta ou isolada as informações provenientes dos índices, assim como, de alguns produtos obtidos a partir de dados de satélites. Dessa forma, é possível identificar, analisar e caracterizar os eventos de seca de uma região. Isso possibilita a realização de planejamentos mais eficazes e mitigações de impactos mais efetivas (Heim e Brewer, 2012; Sivakumar et al., 2011b; Adger et al., 2007; Whilhite et al., 2005).

Em termos nacionais, a Agência Nacional das Águas e Saneamento Básico (ANA) é o órgão responsável pelo sistema de monitoramento do país, ou seja, o Monitor de Secas do Brasil. Além disso, a ANA também conta com a Sala de Situação, que é um outro mecanismo criado para realizar o acompanhamento das situações das precipitações, vazões e níveis dos reservatórios, o que permite um melhor monitoramento de eventos de secas e cheias nas principais bacias hidrográficas do país.

Diante o que foi abordado, o referido artigo trata-se de uma revisão bibliográfica, elaborada com caráter analítico, que tem como proposta discorrer sobre os principais índices utilizados para monitorar as secas, assim como apresentar suas equações e pesquisas realizadas. Além disso, aponta as metodologias de monitoramento e alerta precoce que estão sendo empregadas na atualidade. As informações contidas neste documento, tem como finalidade contribuir para o embasamento e desenvolvimento de futuros trabalhos que tenham como linha de pesquisa os índices de seca ou sistemas de monitoramento.

\section{Metodologia}

A pesquisa pode ser classificada como exploratória, qualitativa e com caráter analítico (Gil, 2002) e foi conduzida por meio de cinco etapas: 1) revisão da literatura; 2) delimitação da pesquisa; 3 ) revisão exploratória; 4) elaboração do texto; 5) análise e síntese dos resultados.

O primeiro passo envolveu a revisão de fontes bibliográficas, como artigos e livros sobre o tema secas, com 
a finalidade de compreender esse fenômeno, assim como, suas características e classificações. A próxima etapa compreendeu a delimitação da pesquisa, onde interessou a identificação dos principais índices de seca e das metodologias que são utilizadas atualmente para monitorar esses eventos. A partir do que foi selecionado, iniciou-se uma revisão exploratória com foco em trabalhos que abordassem a temática escolhida. Em seguida, foi realizada a construção do texto e por último o resumo e análise dos resultados.

\section{Resultados e Discussão}

\section{1. Índices de seca}

Os índices são representações numéricas que expressam e quantificam, por meio de valores, a severidade e magnitude das secas, facilitando a determinação e interpretação de um evento ou característica. Para isso, os índices utilizam dados provenientes de indicadores, assim como, informações climáticas e hidrometeorológicas (Yihdegol et al., 2019; Svoboda e Fuchs, 2016; Sobral et al., 2011; Jannuzzi, 2004; Valipour, 2013; Jang et al., 2017).

A elaboração dos índices permite realizar o agrupamento e condensação das informações presentes nos diversos indicadores disponíveis. De modo geral, a construção de um índice, obedece a três etapas básicas, sendo elas: (a) obtenção dos dados brutos (primários e posterior análise); (b) utilização dos dados para a confecção dos indicadores e (c) junção dos indicadores para compor o índice (Sobral et al., 2011; Siche et al., 2007). A Fig. 1 exibe os passos para se obter um índice, assim como, o grau de agregação dos dados.

Os índices de seca foram criados com o intuito de identificar, avaliar e monitorar o grau de severidade da seca e o seu tempo de duração. Além disso, podem se adaptar a diferentes perspectivas ou categorias de seca. São considerados ferramentas úteis para a compreensão e avaliação dos fenômenos meteorológicos, hidrológicos e agrícolas, pois são responsáveis pelo monitoramento, caracterização temporal e espacial. O uso dos índices, quando aliados a outras técnicas de análise, possibilitam identificar padrões de variabilidade temporal e espacial e tendências dentro das regiões em estudo (Medeiros, 2016; Rosa, 2011).

Foi observado por Mishra e Singh (2010) e Panu e Sharma (2002) que uma variável de seca deve ser capaz de quantificar a seca para diferentes escalas temporais, para qual uma longa série histórica é essencial. Uma série temporal de índices de seca fornece uma estrutura básica para avaliar parâmetros de interesses e assim gerar uma referência. A escala de tempo mais utilizada para analisar esses eventos é a anual, seguida pela mensal.

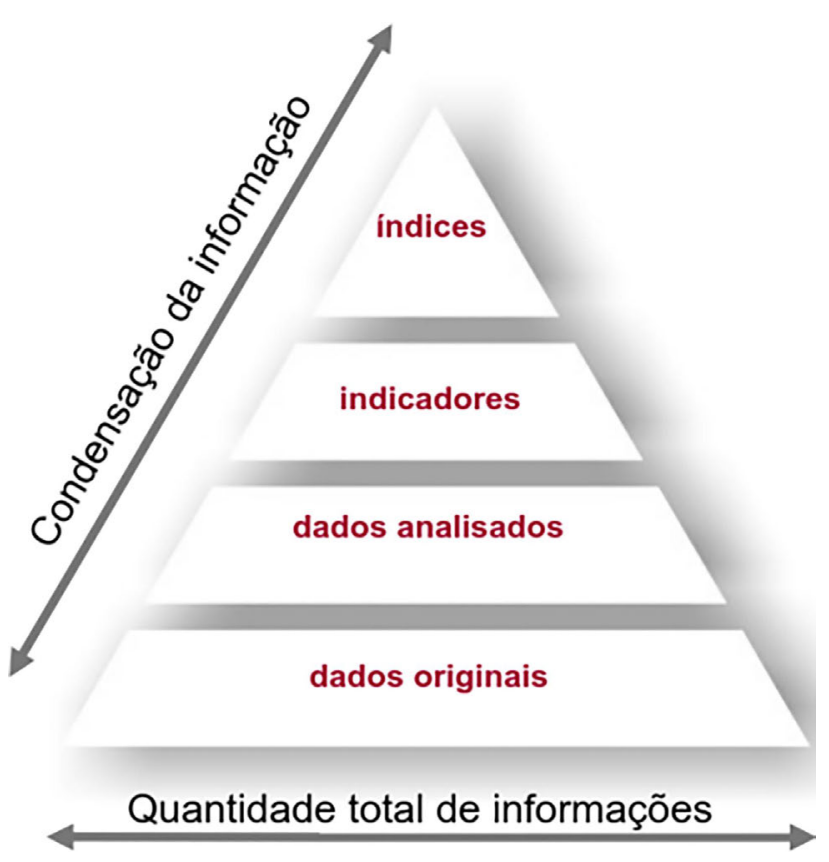

Figura 1 - Pirâmide de agregação de informações. Fonte: Magalhães Júnior (2007).

Até o momento, não existe um único indicador ou índice que seja aplicável para monitorar todos os tipos de seca, cada um possui a sua especificidade. Praticamente, todos os índices utilizam como variável de entrada a precipitação, seja ela de forma individual ou combinada com outros elementos. Essa combinação vai depender de qual tipo de seca se deseja monitorar. Por exemplo, a associação de variáveis como temperatura, precipitação, vazão e nível, nos fornece um índice hidrometeorológico. Já a junção da precipitação com a umidade do solo, proporciona a geração de um índice de umidade. Essas combinações são feitas, com o intuito de gerar diferentes tipos de índices para monitorar os diversos tipos de seca (Svoboda e Fuchs, 2016; Mishra e Singh, 2010).

Uma vez que é feita a identificação e definição de quais índices são os mais adequados para uma região, pode haver uma recomendação de uso e vinculação das ações dentro de um plano de seca (Yihdegol et al., 2019).

\subsection{Aplicações dos índices de seca}

As variáveis como precipitação, vegetação, umidade do solo e armazenamento hídrico podem ser utilizadas como dados de entrada para calcular diversos índices e, dessa forma, realizar o monitoramento dos eventos de seca de uma região (Svoboda e Fuchs, 2016).

\subsubsection{Precipitação}

O estudo da precipitação possibilitou o desenvolvimento de vários índices que tem por finalidade identificar o déficit dessa variável, tais como: Índice de Precipitação Padronizado (Standardized Precipitation Index - SPI), 
Índice de Precipitação e Evapotranspiração Padronizado (Standardized Precipitation-Evapotranspiration Index SPEI), Índice da Anomalia da Precipitação (Anomaly Precipitation Index), Índice Chinês Z (China Z Index), entre outros. Dentre os índices citados, destaca-se o SPI, o qual tem sido amplamente utilizado em pesquisas e foi reconhecido pela Organização Mundial de Meteorologia (WMO), como um índice de referência global para os estudos de seca meteorológica (Ribeiro Neto, 2017; Hayes et al., 2011; Fernandes et al., 2009).

\subsubsection{Standardized Precipitation Index - SPI}

O SPI foi desenvolvido pelos autores Mckee; Doesken e Kleist em 1993 como uma opção a utilização do Índice de Seca de Palmer (Palmer Drought Severity Index - PDSI), pois o mesmo apresentava dificuldades para ser calculado e limitações de uso. O SPI quantifica o déficit de precipitação nas diversas escalas de tempo e ajuda a avaliar a severidade da seca (Ribeiro Neto, 2017; Svoboda e Fuchs, 2016; Fernandes et al., 2009; Patel et al., 2007; Guttman, 1998).

O cálculo do SPI (Eqs. (1) e (2)) é feito baseando-se nos dados mensais de precipitação acumulada para um intervalo de tempo de $n$ meses. Essas séries são submetidas a uma função Gama, e logo após, são calculadas as probabilidades de ocorrência de cada valor de precipitação. Em seguida, aplica-se a inversa da distribuição normal para encontrar os desvios de precipitação em relação à média para os intervalos analisados (Santos, 2020; Martins et al., 2015; Patel et al., 2007; Mckee et al., 1993).

$$
\begin{aligned}
& S P I=-\frac{\left(t-C_{0}+C_{1} t+C_{2} t^{2}\right)}{1+d_{1} t+d_{2} t^{2}+d_{3} t^{3}} \quad \text { Se } 0<H(x)<0,5 . \\
& S P I=+\frac{\left(t-C_{0}+C_{1} t+C_{2} t^{2}\right)}{1+d_{1} t+d_{2} t^{2}+d_{3} t^{3}} \quad \text { Se } 0,5<H(x)<1 .
\end{aligned}
$$

em que $t=\sqrt{ } \ln \left[1 /(H(x))^{2}\right]$ para $0<H(x)>0,5$ e $t=\sqrt{ } \ln$ $\left[1 /\left(1-(H(x))^{2}\right)\right]$ para $0,5<H(x)<1 ; H(x)=$ distribuição de probabilidade acumulada; $C_{0}, C_{1}, C_{2}, d_{1}, d_{2}$ e $d_{3}$ são constantes e equivalem respectivamente aos valores: 2,$515517 ; 0,802853 ; 0,010328 ; 1,432788 ; 0,189269$; 0,001308 .

Utiliza-se o SPI que foi acumulado em intervalos relativos a três e quatro meses para identificar possíveis secas de curto prazo, e para identificação de secas de longo prazo adotam-se os intervalos de doze, dezoito e vinte e quatro meses. Assim como, para o intervalo de seis meses objetivando a verificação da transição entre os períodos de curto e longo prazo (Svoboda e Fuchs, 2016; Martins et al., 2015; Fernandes et al., 2009; Mckee et al., 1993).

O SPI apresenta uma série de vantagens associadas ao seu uso, sendo elas: possibilidade de determinação do tempo de retorno da seca, ampla flexibilidade (aplica-se em diferentes escalas temporais), simplicidade de aplica- ção, versatilidade (pode ser combinado com outras variáveis), capacidade de adequação às diversas situações climáticas (permite a análise espacial e a comparação de diferentes regiões), possibilita o monitoramento e aviso prévio da seca (Santos, 2020; Svoboda e Fuchs, 2017; Santos e Portela, 2010; López-Moreno et al., 2009; Fernandes et al., 2009).

Em contrapartida, as desvantagens do SPI consistem na necessidade de séries que tenham no mínimo 30 anos de dados contínuos de precipitação. Essa condição, pode representar uma dificuldade para se realizar o cálculo do índice, pois existem regiões que apresentam baixa disponibilidade de dados pluviométricos e uma reduzida série histórica de produtos gerados através de sensoriamento remoto. Além disso, se ocorrerem mudanças ou erros nos dados ofertados pelas instituições, os valores de SPI podem mudar e deixar de representar o estado de seca (Santos, 2020; Svoboda e Fuchs, 2017; Santos e Portela, 2010; Fernandes et al., 2009).

Diversos estudos já foram realizados para analisar a capacidade do SPI em identificar e caracterizar eventos de secas. Por exemplo, os trabalhos desenvolvidos por Ganapathi (2018), Zarch et al. (2015) e Wu et al. (2007), onde o primeiro utilizou as informações advindas do índice para identificar a gravidade da seca no Distrito Ahmednagar, na Índia. $\mathrm{O}$ autor constatou que o SPI pode ser usado como ferramenta para fins de avaliação e monitoramento da seca na região, podendo ser aplicado em diversas escalas temporais e espaciais, com o intuito de trazer uma melhor análise da severidade da seca. No segundo estudo, os autores analisaram a tendência de ocorrência de secas, no período de 1960 a 2009, para as várias zonas climáticas do planeta. Com isso, eles chegaram a conclusão de que o SPI não tem a capacidade de identificar secas futuras diante da ocorrência do aquecimento global, necessitando assim, ser associado a outros índices. Já a terceira pesquisa, analisou a atuação do clima árido e dos períodos secos na determinação do SPI de curto prazo para os EUA. Neste estudo, os autores concluíram que, quando existe uma grande quantidade de dias sem ocorrência de precipitação (valor zero), os valores de SPI não indicam adequadamente a ocorrência de secas. Além disso, os autores pedem aos usuários que sejam cautelosos ao aplicar e analisar os valores de SPI em regiões com regimes climáticos variáveis, no caso de clima mais secos, deve-se focar na duração da seca e não apenas na sua gravidade.

Em termos nacionais, os pesquisadores Silva et al. (2020), Gandu et al. (2015), Fechine (2015), Macedo et al. (2011) e Blain et al. (2010) realizaram estudos com o intuito de aplicar o SPI no monitoramento e caracterização das secas para os estados, utilizando uma escala regional, que foi adaptada para a área de estudo. O trabalho realizado por Silva et al. (2020) buscou caracterizar os eventos extremos e suas causas climáticas através da utilização do SPI para o Leste do Nordeste Brasileiro. Desse modo, eles 
concluiram que, o SPI mostrou-se capaz de quantificar eventos de seca ou de abundância de chuvas, assim como monitorar a precipitação, revelando ser uma ferramenta eficiente para ser utilizada na mitigação de secas.

Neste mesmo contexto, os pesquisadores Gandu et al. (2015) buscaram identificar os eventos de seca ocorridos no estado do Ceará, através do SPI. Dessa forma, eles constaram que, o SPI nas escalas entre 24 e 36 meses mostraram identificar bem o início e a duração da seca hidrológica no estado. Já o estudo realizado por Fechine (2015), teve como finalidade identificar as secas metorológicas na região Metropolitana de Fortaleza, através do SPI. Para a realização da pesquisa, foi utilizado o SPI na escala quadrimestral (04 meses), correspondendo aos meses de fevereiro à maio. Os eventos de seca apontados pelo índice foram correlacionados com os episódios de El Ninõ, La Niña, Dipolo do Atlântico Tropical e com a posição da Zona de Convergência Intertropical (ZCIT). Desse modo, verificou-se que, quase todos os eventos de seca encontrados pelo índice foram em anos de atuação do fenômeno El Ninõ, em conjunto com o gradiente meridional de anomalia da Temperatura de Superfície do Mar (TSM). Além disso, também foi observado pelo autor que, as principais secas ocorridas na área de estudo, foram classificadas entre moderadas a severas.

A pesquisa executada por Macedo et al. (2011), teve como objetivo realizar o monitoramento e a identificação da intensidade das secas, assim como dos períodos chuvosos para a cidade de Campina Grande, localizada no estado da Paraíba. Para isso, os autores utilizaram o SPI em diversas escalas temporais $(01,03,06,12$ e 24$)$ e constataram que, o índice expressa de forma satisfatória a realidade pluviométrica da região. Neste mesmo contexto, os pesquisadores Gandu, Silva e Martins (2015) buscaram identificar os eventos de seca ocorridos no estado do Ceará, através do SPI. Dessa forma, concluiram que, o SPI nas escalas entre 24 e 36 meses mostraram identificar bem o início e a duração da seca hidrológica no estado.

O trabalho realizado por Blain et al. (2010) aplicou o SPI nas condições de seca no Espírito Santo. Com a pesquisa, os estudiosos concluíram que, o índice pode ser utilizado no estado para o monitoramento da seca meteorológica. Além disso, constatou-se que a principal característica das séries de SPI foi a grande variabilidade espacial e temporal, indicando que uma mesma região pode apresentar períodos secos, seguidos de meses normais ou úmidos e que diferentes tipos de secas podem ocorrer na região em um mesmo espaço de tempo.

Além disso, vários trabalhos têm mostrado que é viável utilizar dados de precipitação advindos de satélites no cálculo do SPI, e que essa técnica apresenta concordância quando comparada aos valores de SPI obtidos através de dados de sensoriamento remoto e postos pluviométricos (Sousa Júnior et al., 2021; Yan et al., 2014; Naumann et al., 2012; Rhee et al., 2010).

\subsubsection{Vegetação}

A identificação das alterações na vegetação, ocasionadas pelo déficit hídrico, e o acompanhamento das secas agrícolas, podem ser realizados por meio de índices, desenvolvidos e aprimorados ao longo dos anos. Têm-se, por exemplo, o Índice de Condição Vegetal (Vegetation Condition Index - VCI), o Índice de Saúde da Vegetação (Vegetation Health Index - VHI) e o Índice de Vegetação Padronizada (Standardized Vegetation Index - SVI), os quais utilizam como dados de entrada os valores do Índice de Vegetação por Diferença Normalizada (Normalized Difference Vegetation Index - NDVI) (Inocêncio et al., 2020; Ribeiro Neto, 2017; Fernandes et al., 2009).

\subsubsection{Normalized Difference Vegetation Index - NDVI}

O NDVI é uma ferramenta que se baseia nas informações de sensoriamento remoto para estimar a vegetação viva através do nível da atividade fotossintética da cultura monitorada. Seu cálculo (Eq. (3)) baseia-se na porção visível (região onde a vegetação exibe uma maior refletância - VIS) e do infravermelho próximo (faixa em que a vegetação apresenta uma maior absorção da luz em razão da presença de clorofila - NIR). (Santos, 2020; Ribeiro Neto, 2017; Gates, 1970 apud Kogan, 2002; Rouse et al., 1973).

$$
N D V I=\frac{N I R-V I S}{N I R+V I S}
$$

em que $N I R=$ infravermelho próximo $(0,725$ a $1,100 \mu \mathrm{m})$; $V I S=$ região do vermelho visível $(0,40$ a $0,700 \mu \mathrm{m})$.

Os valores de NDVI variam entre -1 a 1 , onde valores negativos representam as áreas de corpos hídricos e sombra. Valores positivos e mais próximos do zero correspondem às áreas de solo sem cobertura vegetal e valores mais próximos de 1 estão relacionados com a presença de vegetação. Em situações de seca, ocorre uma diminuição da pigmentação verde, levando assim, a um aumento do VIS e uma diminuição do NIR (Santos, 2020; Meneses e Almeida, 2012; Gates, 1970 apud Kogan, 2002).

Este índice apresenta como vantagens a facilidade de processamento e obtenção dos dados. Além disso, pode ser utilizado para realizar o acompanhamento das alterações sazonais no ciclo de vida das plantas. Já as limitações, consistem na ocorrência de erros técnicos associados aos sensores ou computação dos dados, nas interferências provocadas pela coloração dos solos e na existência de água que pode estar presente na vegetação ou no solo (Silveira Júnior et al., 2019; Ribeiro Neto, 2017; Johan et al., 2012).

Neste âmbito, a pesquisa desenvolvida por Silveira Júnior et al. (2019) teve como proposta utilizar a nível nacional os dados do satélite Meteosat-10 para gerar o NDVI. Os autores apontaram que, o Meteosat apresenta uma boa eficiência ao monitorar a vegetação através do 
NDVI para regiões da África, estando altamente correlacionado com os dados de satélites de órbita polar. Dessa forma, ele pode ser utilizado para analisar o estresse hídrico e o crescimento fenológico das plantas. Os pesquisadores também destacam que, existem limitações (resolução espacial, qualidade da imagem, canais espectrais utilizados e correções a níveis atmosféricos e geométricos) que devem ser levadas em consideração ao tentar gerar o NDVI a partir dos dados do Meteosat no Brasil, pois estas podem influenciar diretamente na qualidade do produto gerado.

O trabalho realizado por Neiverth et al. (2013) retratou o NDVI dos estádios fenológicos da soja que apresentavam crescimento indeterminado em casas de vegetação. Com o estudo foi possível concluir que, o NDVI consegue retratar e diferenciar o crescimento fenológico da vegetação analisada, além disso, observou-se que o valor do índice aumenta em $12,7 \%$ com o início da fase de floração e diminui em locais com baixa cobertura vegetal.

Os pesquisadores Samanta et al. (2010) e Saleska et al. (2007) utilizaram a mesma área de estudo em seus trabalhos, a floresta Amazônica. A primeira pesquisa apontou que, mesmo apresentando vulnerabilidades às secas de longo e curto prazo, dados de satélites mostraram que houve um aumento da taxa fotossíntética em 2005, período em que a floresta enfrentou uma seca curta, mas de grande intensidade. Desse modo, foi possível concluir que, a floresta pode ser mais resistente do que os modelos baseados em ecossistemas apontam. Já o segundo trabalho, contestou os resultados apresentados por Saleska et al. (2007) onde foi demonstrado que os dados utilizados para analisar o verdejamento ou escurecimento das plantas na região Amazônica eram insuficientes para apontar conclusões sobre a variação espacial da vegetação, além disso, os autores ainda apontaram que, a floresta Amazônica não esteve verde na seca ocorrida em 2005.

\subsubsection{Umidade do solo}

A umidade do solo é uma variável que deve ser considerada quando se deseja monitorar e caracterizar os episódios de seca agrícola de uma região. A ocorrência de precipitações abaixo da média por longos períodos, acaba por provocar uma diminuição na umidade do solo, e consequentes impactos na vegetação. (Inocêncio et al., 2020; Pablos et al., 2017; Rossato et al., 2017; Souza et al., 2018).

As metodologias utilizadas para se medir a umidade do solo em campo geralmente possuem o custo muito elevado e demandam uma grande quantidade de tempo. Devido a isso, muitas áreas acabam por não dispor de estações agrometeorológicas para coleta de dados sobre essa variável (Inocêncio et al., 2020; Pablos et al., 2017; Rossato et al., 2017; Souza et al., 2018).

Os valores de umidade do solo podem ser estimados através de modelos hidrológicos ou de superfície e de pro- dutos gerados através do sensoriamento remoto. Alguns sensores apresentam uma importância significativa na geração desses dados, sendo eles: Umidade do Solo e Salinidade do Oceano (Soil Moisture and Ocean Salinity SMOS), Sensor Remoto Europeu (European Remote Sensing - ERS), Umidade do Solo Ativa e Passiva (Soil Moisture Active Passive - SMAP) e Radiômetro Avançado por Varredura de Microondas (Advanced Microwave Scanning Radiometer - AMSR-E). Vale ressaltar que, os dados provenientes do sensoriamento remoto podem ser gerados a nível global, porém o baixo número de anos impossibilita estudos sobre eventos hidrológicos do passado (Inocêncio et al., 2020; Pablos et al., 2017; Rossato et al., 2017; Souza et al., 2018).

Ao longo dos anos, foram desenvolvidos diversos índices que utilizam a umidade do solo como variável de entrada. Pode-se citar como exemplo: Índice de Umidade da Cultura (Crop Moisture Index - CMI), Índice de Condição da Umidade do Solo (Soil Moisture Condition Index - SMCI), Índice de Anomalia da Umidade do Solo (Soil Moisture Anomaly Index - SMA), Índice de Déficit de Evapotranspiração (Evapotranspiration Deficit Index ETDI), Índice de Déficit da Umidade do Solo (Soil Moisture Deficit Index - SMDI), Índice Padronizado de Umidade do Solo (Standardized Soil Moisture Index - SSMI), Índice de Estresse Hídrico da Cultura (Crop Water Stress Index - CWSI), Índice de Déficit de Umidade do Solo (Soil Moisture Deficit Index - SMDI) e Índice de Armazenamento de Água no Solo (Soil Water Storage Index - SWS) (Inocêncio et al., 2020; Souza et al., 2018; Pablos et al., 2017; Rossato et al., 2017; Carrão et al., 2016; Svoboda e Fuchs, 2016; Fernandes et al., 2009).

\subsubsection{Crop Moisture Index - CMI}

O CMI foi proposto por Palmer (1968) para analisar as condições de umidade do solo nas regiões de produção agrícola utilizando uma curta escala de tempo. Seu cálculo (Eq. (4)) inclui as variáveis umidade do solo, precipitação e temperatura e sua obtenção é feita através da subtração entre a anomalia da evapotranspiração potencial e a umidade do solo, de maneira a identificar possíveis déficits.

$$
C M I=I A E-U S
$$

em que IAE = Índice de Anomalia de Evapotranspiração, obtido através da equação $\left(E t p_{\text {observada }}-E_{t} p_{\text {média }}\right)$ / desvio padrão da Evapotranspiração; $U S=$ Umidade do Solo.

As informações geradas pelo índice, são repassadas semanalmente, onde os valores são influenciados diretamente pelas condições locais e pelo tempo, portanto, o $\mathrm{CMI}$ tem a capacidade de responder rapidamente às mudanças. Apresenta como vantagem a identificação da seca agrícola, porém não é eficiente para monitorar secas de longo prazo (Svoboda e Fuchs, 2016; Fernandes et al., 2009). 
O CMI vem sendo utilizado desde 1973 pelo Sistema Integrado Nacional de Informação sobre a Seca dos Estados Unidos (National Integrated Drought Information System - NIDIS). Atualmente, seu cálculo é feito para 350 divisões climáticas localizadas nos EUA e em Porto Rico e tem por finalidade medir o estado da seca ou umidade do solo que afeta diretamente as safras e as atividades agrícolas (NIDIS, 2021).

\subsubsection{Recursos hídricos}

A disponibilidade e o armazenamento hídrico de uma região são condições que devem ser consideradas em estudos sobre a seca, principalmente, naqueles que envolvem as consequências desses eventos nos recursos hídricos superficiais. As informações utilizadas para essas pesquisas podem advir da coleta de dados dos postos fluviométricos, do monitoramento dos níveis dos corpos d'água, dos modelos hidrológicos e dos produtos gerados através do sensoriamento remoto (Ribeiro Neto, 2017; Fernandes et al., 2009).

Os índices que necessitam dos valores da vazão e nível de corpos hídricos como dados de entrada, de forma isolada ou combinada com demais variáveis (meteorológicas e hidrológicas), são geralmente, os que possuem uma maior capacidade em repassar informações sobre o estado hídrico de uma área. Os principais índices desenvolvidos nos últimos anos, são: Índice de Abastecimento de Água Superficial (Sufarce Water Suply Index - SWSI), Índice de Recuperação de Seca (Reclamation Drought Index - RDI), Índice de Vazão Padronizado (Standardizerd Flow Index - SSFI), Índice Padronizado de Escoamento (Standardizerd Runoff Index - SRI) e Índice de Seca de Vazão (Flow Dryness Index - SDI) (Ribeiro Neto, 2017; Svoboda e Fuchs, 2016; Fernandes et al., 2009).

O SSFI e o SDI são exemplos de ferramentas que aplicam apenas a componente vazão em seu cálculo. $\mathrm{O}$ primeiro foi criado por Modarres (2007) e utiliza a distribuição normal na sua equação. Já o SDI, proposto por Nalbantis e Tsakiris (2008), possui uma metodologia de cálculo bem parecida com a do SSFI, diferenciando-se apenas pela forma que o dado de entrada é inserido, ou seja, ele usa a vazão acumulada anual.

\subsubsection{Sufarce Water Suply Index - SWSI}

O SWSI foi elaborado por Shafer e Dezman (1982) no estado do Colorado, com a finalidade de fornecer um indicador mais apropriado para analisar a disponibilidade de água na região oeste dos Estados Unidos. Este índice, associa características hidrológicas e meteorológicas para se obter apenas um valor, sendo classificado como um índice hidrometeorológico. Com isso, é possível avaliar a disponibilidade de água de uma região, fornecendo uma medida representativa da situação hídrica de uma bacia ou local de estudo.
Deste modo, permite a comparação das condições de abastecimento hídrico entre bacias para a avaliação da severidade de seca relativa. Por isso, é uma boa ferramenta para monitorar o impacto da seca hidrológica no abastecimento urbano, industrial, na irrigação e geração de energia hidrelétrica (Andrade, 2016; Fernandes et al., 2009; Mishra e Singh, 2010).

Para determinar o SWSI de uma bacia de um reservatório em particular, dados mensais de precipitação, vazão e nível do reservatório são coletados e somados para todas as estações de medição sobre a bacia. Cada componente deve ser normalizado usando-se uma análise de frequência acumulada de uma série de dados históricos. Para cada mês, os valores de cada componente medido em todas as estações (ou reservatórios) são somados, tendo um peso atribuído, dependendo da sua contribuição para a água em superfície dentro dessa bacia. Esses componentes ponderados são somados para determinar um valor de SWSI representando a bacia inteira (Valipour, 2013; Fernandes et al., 2009; Garen, 1993; Shafer e Dezman, 1982).

Cada soma é normalizada e sua probabilidade de não-excedência é determinada com base na análise de frequência. A utilização do conceito de probabilidade de nãoexcedência é de fundamental importância, pois permite a comparação da disponibilidade de abastecimento de água entre regiões de diferentes variabilidades (Valipour, 2013; Fernandes et al., 2009; Garen, 1993, Shafer e Dezman, 1982). A Eq. (5) apresenta o cálculo do SWSI.

$$
S W S I=\frac{[(a * \text { Pprecipitação })+(b * \text { Pvazão })+(c * \text { Pnivel })]-50}{12}
$$

em que $a, b$ e $c=$ coeficientes para a precipitação sobre área de drenagem do reservatório, a vazão afluente no reservatório e o nível do reservatório, respectivamente, e devem atender à condição: $a+b+c=1 ; P i=$ probabilidade (\%) de não-excedência para cada um destes componentes.

As operações de subtração por 50 e divisão por 12 são requeridas para fazer os valores do SWSI terem uma escala similar ao Índice de Palmer (PDSI). Este índice de abastecimento é centrado em zero e tem uma escala entre -4,0 e 4,0 (Garen, 1993; Shafer e Dezman, 1982).

De acordo com Keyantash e Dracup (2002) os índices de seca apresentam potencialidades e deficiências. Em seu trabalho, ele buscou avaliar como essas características estão relacionadas, para que possam ser atribuídas pontuações de acordo com o desempenho do índice. Essa avaliação é feita comparando-se diferentes índices de seca hidrológica, baseando-se em critérios como: robustez, tratabilidade, transparência, sofisticação, extensibilidade e dimensionabilidade. Ao avaliar o SWSI, os valores obtidos nessa classificação foram: $80 \%$ de robustez, $20 \%$ de tratabilidade, $40 \%$ de transparência, $60 \%$ de sofisticação, $40 \%$ de extensibilidade e $60 \%$ de dimensionabilidade. Os 
autores concluíram que, este índice pode ser considerado uma boa ferramenta para o monitoramento hídrico.

O SWSI tem sido abordado também em trabalhos como os de Garen (1993) e Valipour (2013), onde o primeiro autor trata sobre a aplicação e adaptação do índice para o Ocidente dos Estados Unidos. Dessa forma, ele conclui que, o índice pode ser utilizado para fins de monitoramento e gestão das secas na região, sendo uma ferramenta útil para os gestores e tomadores de decisão. $\mathrm{O}$ segundo trabalho disserta sobre a utilização do SWSI na avaliação e na gestão dos recursos hídricos em Colorado e Oregon (EUA). Para o desenvolvimento da pesquisa, o autor utilizou dados de 30 anos (1982 até 2011) e calculou o SWSI para 21 bacias, sendo 7 localizadas no Colorado, apresentando clima Continental e 14 bacias em Oregon, com clima mais ameno. Desse modo, o autor constatou que, os estados de seca hidrológica nas bacias variavam entre extremamente úmido até seca extrema e que a visualização gráfica dos valores do índice permite que os usuários identifiquem anos críticos e tendências de comportamento e, dessa forma, determinem estratégias para lidar com o abastecimento hídrico. Além disso, verificou-se que o SWSI é uma excelente ferramenta de monitoramento e gestão estratégica da água, uma vez que, o índice tem uma grande capacidade de avaliar as condições hidrológicas e a gestão da água na agricultura. Também é evidenciado pelo autor que, o componente reservatório é a força motriz predominante no cálculo do índice.

\subsection{Monitoramento das secas}

Segundo Santos (2020) e Zink et al. (2016) é possível destacar alguns sistemas de monitoramento e alerta precoce das secas que estão sendo utilizados com êxito e encontram-se bem consolidados nas regiões onde foram desenvolvidos, podendo-se citar: Monitor de Secas dos Estados Unidos (United States Drought Monitor USDM), Monitor de Secas Norte Americano (North American Drought Monitor - NADM), Monitor de Secas Europeu (European Drought Monitor - EDO), Monitor de Enchentes e Secas na África (African Flood and Drought Monitor - AFDM), Monitor de Enchentes e Secas na América Latina (Latin America Flood and Drought Monitor - LAFDM); Monitor de Secas da Alemanha (Germany Drought Monitor - GDM), Monitor de Secas da Índia, Monitor de Secas do México (Monitor de Sequía em México-MSM) e Monitor de Secas do Brasil.

\subsubsection{United States Drought Monitor - USDM}

O USDM foi desenvolvido em 1999, a partir da ação conjunta da Administração Nacional Oceânica e Atmosférica (National Ocean and Atmosphere Administration NOAA), do Departamento de Agricultura dos Estados Unidos (U.S. Departament of Agriculture - USDA) e do Centro Nacional de Mitigação da Seca da Universidade de Nebraska-Lincoln, sendo o primeiro sistema de acompa- nhamento e previsão de secas implantado no mundo (Wilhite, 2014).

Utiliza uma grande variedade de índices e produtos de apoio, sendo eles: PDSI, Índice de Resposta à seca de Vegetação (Vegetation Drought Response Index - VegDRI), Percentis do modelo de umidade do solo do Centro de Previsão Climática (Climate Prediction Center - CPC), Percentis de vazão semanal do Serviço Geológico dos EUA (United States Geological Survey - USGS), SPI, Análise de Precipitação do Serviço Nacional de Meteorologia (National Weather Service), Boletim de tempo e colheita semanal, Índice de Umidade de Colheita (Crop Moisture Index), Porcentagem de precipitação Normal, dados de vazão e umidade do solo, produtos de saúde de vegetação global e mapas de risco de incêndio (Santos, 2020; U.S. Drought Monitor, 2020).

As informações geradas pelo USDM são divulgadas semanalmente na forma de mapas e relatórios. Os mapas apresentam cinco categorias de seca, sendo: D0 (seca anormal), D1 (seca moderada), D2 (seca severa), D3 (seca extrema) e D4 (seca excepcional). Esses mapas contêm informações importantes sobre a ocorrência, severidade, dimensão e impactos da seca e seus resultados são utilizados por agências e instituições governamentais do país para acionar planos e medidas de combate à esses eventos (Chen et al., 2019).

A Fig. 2 apresenta o mapa semanal para o mês de janeiro de 2021. Cada cor representa a categoria de seca em que se encontra a região analisada e as letras $\mathrm{S}$ e $\mathrm{L}$ indicam os impactos de curto e longo prazo, respectivamente. Os impactos de curto prazo ocorrem normalmente com uma escala menor que 6 meses e afetam, por exemplo, a agricultura e as pastagens. Enquanto isso, os impactos de longo prazo acontecem em escalas maiores que 6 meses e refletem diretamente na disponibilidade dos recursos hídricos e no meio ambiente.

A Tabela 1 mostra a classificação da seca e os impactos associados a ocorrência desses eventos.

\subsubsection{North American Drought Monitor - NADM}

O NADM é um sistema de monitoramento que avalia as condições atuais de seca a partir de uma base continental. Ele é produzido a partir da colaboração entre três países (Canadá, México e EUA), e suas informações são repassadas de forma mensal, através da utilização dos seguintes índices: SPI, PDSI, Porcentagem da precipitação média de longo prazo, Umidade do solo modelada do Centro de Previsão do Clima da NOAA e Índices de saúde da vegetação derivados de satélite (Heim e Brewer, 2012; Sivakumar et al., 2011a).

Cada país prepara de forma individual suas próprias descrições sobre a seca. Os autores principais são alternados e designados pelas seguintes instituições: NOAA, Departamento de Agricultura dos Estados Unidos, Centro Nacional de Mitigação de Secas dos Estados Unidos, 
MONITOR DESECAS DOS ESTADOS UNIDOS

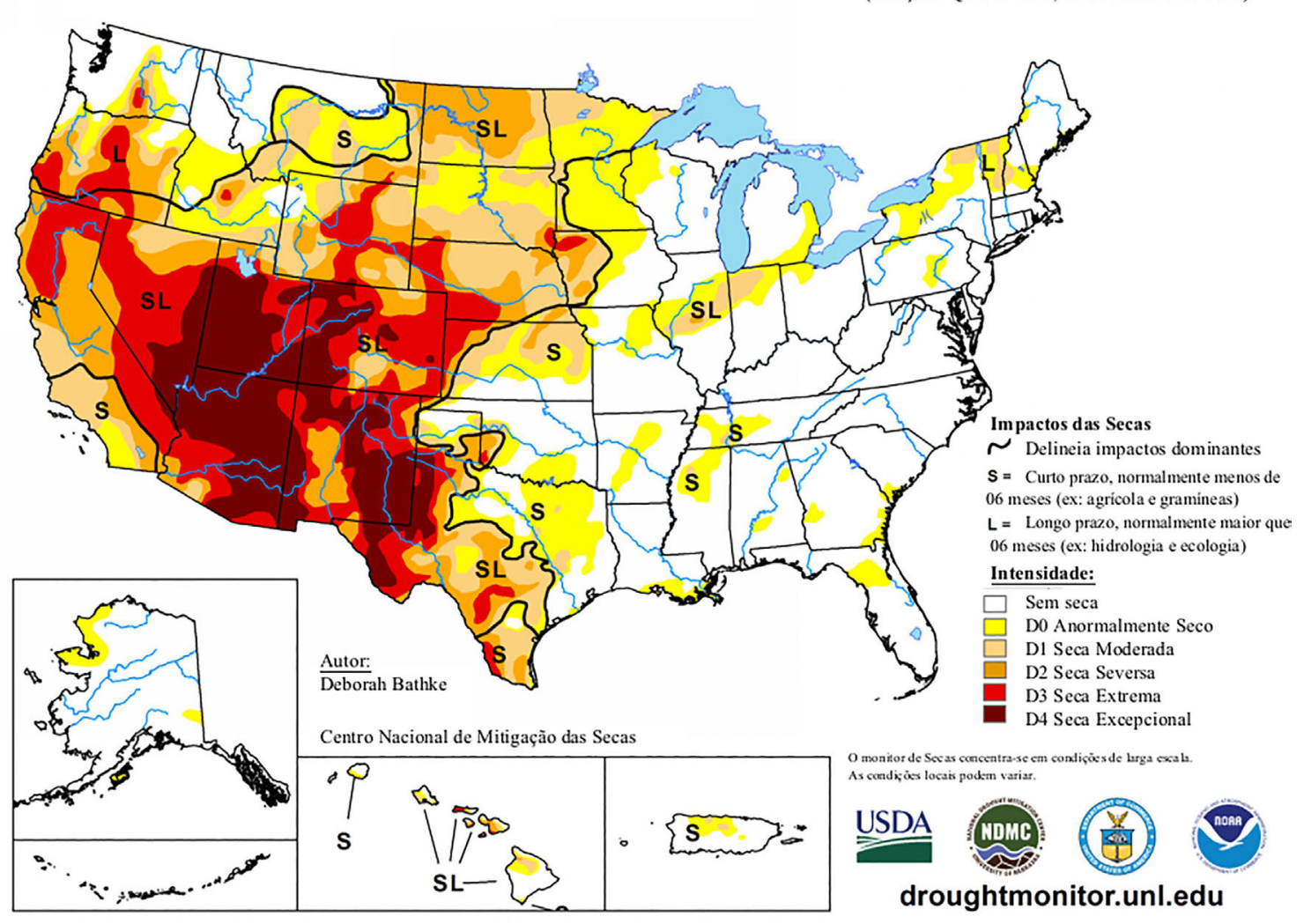

05 de Janeiro de 2021

(Lançado Quinta-feira, 07 de Janeiro de 2021)

Figura 2 - Monitor de Secas dos Estados Unidos: 05 de janeiro à 12 janeiro de 2021. Fonte: Adaptado do Monitor de Secas dos Estados Unidos (2021).

Tabela 1 - Classificação da seca e dos seus possíveis impactos de acordo com o Monitor de Secas dos Estados Unidos.

\begin{tabular}{|c|c|c|c|c|c|c|c|}
\hline Categoria & Descrição & Impactos & PDSI & $\mathrm{CPC}$ & USGS & SPI & $\begin{array}{l}\text { Mistura de Indica- } \\
\text { dores de Seca } \\
\text { (Percentis) }\end{array}$ \\
\hline D0 & $\begin{array}{l}\text { Anormalmente } \\
\text { Seco }\end{array}$ & $\begin{array}{c}\text { Entrando cm seca: Seca de curto prazo retardando o plantio, } \\
\text { o crescimento das safras ou pastagens. Saindo da seca: } \\
\text { Alguns déficits de água persistentes; Colheitas c pastagens } \\
\text { nào totalmente recuperadas. }\end{array}$ & $\begin{array}{c}-1,0 \mathrm{a} \\
-1,9\end{array}$ & $\begin{array}{c}21 \mathrm{a} \\
30\end{array}$ & $\begin{array}{c}21 \mathrm{a} \\
30\end{array}$ & $\begin{array}{c}-0,5 \mathrm{a} \\
-0,7\end{array}$ & 21 a 30 \\
\hline D1 & Seca Moderada & $\begin{array}{c}\text { Alguns danos às colheitas e pastagens; Baixa hídrica de ria- } \\
\text { chos, reservatórios e/ou poços; Solicitação de restrições } \\
\text { voluntárias de uso da água. }\end{array}$ & $\begin{array}{l}-2,0 \mathrm{a} \\
-2,9\end{array}$ & $\begin{array}{c}11 \mathrm{a} \\
20\end{array}$ & $\begin{array}{c}11 \mathrm{a} \\
20\end{array}$ & $\begin{array}{l}-8,0 \text { a } \\
-1,2\end{array}$ & 11 a 20 \\
\hline D2 & Seca Severa & $\begin{array}{l}\text { Prováveis perdas de safra ou pastos; Escassez de água; } \\
\text { Restrições ao uso da água. }\end{array}$ & $\begin{array}{c}-3,0 \mathrm{a} \\
-3,9\end{array}$ & $\begin{array}{l}6 \mathrm{a} \\
10\end{array}$ & 6 a 10 & $\begin{array}{l}-1,3 \mathrm{a} \\
-1,5\end{array}$ & 6 a 10 \\
\hline D3 & Seca Extrema & $\begin{array}{c}\text { Perdas de safra e pastos; Escassez generalizada de água; } \\
\text { Restrições ao uso da água. }\end{array}$ & $\begin{array}{c}-4,0 \mathrm{a} \\
-4,9\end{array}$ & 3 a 5 & 3 a 5 & $\begin{array}{c}-1,6 \mathrm{a} \\
-1,9\end{array}$ & 3 a 5 \\
\hline D4 & $\begin{array}{l}\text { Seca Excepcio- } \\
\text { nal }\end{array}$ & $\begin{array}{l}\text { Perdas generalizadas de safra e pastagens; Escassez hídrica } \\
\text { em reservatórios, riachos e poços; Crise hídrica. }\end{array}$ & $\begin{array}{l}-5,0 \text { ou } \\
\text { menos }\end{array}$ & 0 a 2 & 0 a 2 & $\begin{array}{l}-2,0 \text { ou } \\
\text { menos }\end{array}$ & 0 a 2 \\
\hline
\end{tabular}

Fonte: Adaptado do Monitor de Secas dos Estados Unidos (2021).

Agricultura no Canada e o Serviço Meteorológico Nacional no México (Heim e Brewer, 2012; Sivakumar et al., 2011a).

Esse sistema colaborativo tem funcionado para a América Norte devido às seguintes razões: a) infraestrutura de dados compatível (representações de secas a nível nacional com os arquivos em formato GIS-D4, estrutura previamente acordada); b) extensas bases de dados e observações diárias em cada país; c) acordos de colaboração em vigência, caso seja preciso realizar trocas de dados internacionais e o compartilhamento de experiências para o monitoramento, previsão e estudos 
sobre a seca (Heim e Brewer, 2012; Sivakumar et al., 2011a).

A Fig. 3 exibe o mapa referente ao mês de novembro de 2020. As cores e as categorias de seca são as mesmas utilizadas no USDM, assim como, as dimensões de impacto.

\subsubsection{European Drought Monitor - EDO}

$\mathrm{O}$ EDO tem como principal função monitorar as secas meteorológicas, hidrológicas e agrícolas e para tal, baseia-se nas informações fornecidas pelas seguintes ferramentas: SPI, Anomalia de Condição da Vegetação (Anomaly of Vegetation Condition - fAPAR), Anomalia de Umidade do Solo (Soil Moisture Anomaly - SMA), Índice de Baixo Fluxo (Low Flow Index - LFI), Índice de Ondas de Calor e Frio (Heat and Cold Wave Index - HCWI), Indicador Combinado de Seca (Combined Drought Index CDI) e SPI (EDO, 2020; Zink et al., 2016; Jager e Vogt, 2015; Hannaford et al., 2011).

A Fig. 4 exibe o mapa atual das secas para a Europa, o qual corresponde ao primeiro período de dez dias para o mês de janeiro (2021). A escala de cores corresponde aos efeitos das secas e indica quais são as necessidades do momento. Por exemplo, a cor amarela demonstra que é preciso vigiar o déficit de precipitação, já a laranja aponta um cenário de atenção, pois existe um déficit de umidade do solo. A coloração vermelha indica um alerta para o estresse hídrico apresentado pela vegetação, ocasionado pela baixa umidade do solo e escassez de precipitação.

\subsubsection{African Flood and Drought Monitor-AFDM e Latin America Flood and Drought Monitor - LAFDM}

Os sistemas de monitoramento AFDM e LAFDM, foram criados pela Universidade de Princeton, localizada nos EUA, em parceria com a Organização das Nações Unidas para a Educação, a Ciência e a Cultura (UNES$\mathrm{CO})$. Eles realizam o acompanhamento das secas através dos seguintes índices: SPI (nas escalas de 1, 3, 6 e 12 meses), Percentil de vazões (simuladas através modelo hidrológico VIC), Percentil do NDVI (para uma média móvel de 30 dias). Porém, vale destacar que, as informações geradas a partir dos índices, são utilizadas de forma

\section{MONITOR DE SECAS NORTE AMERICANO}

30 de Novembro de 2020

(Lançado Terça-feira, 10 de Dezembro de 2020)

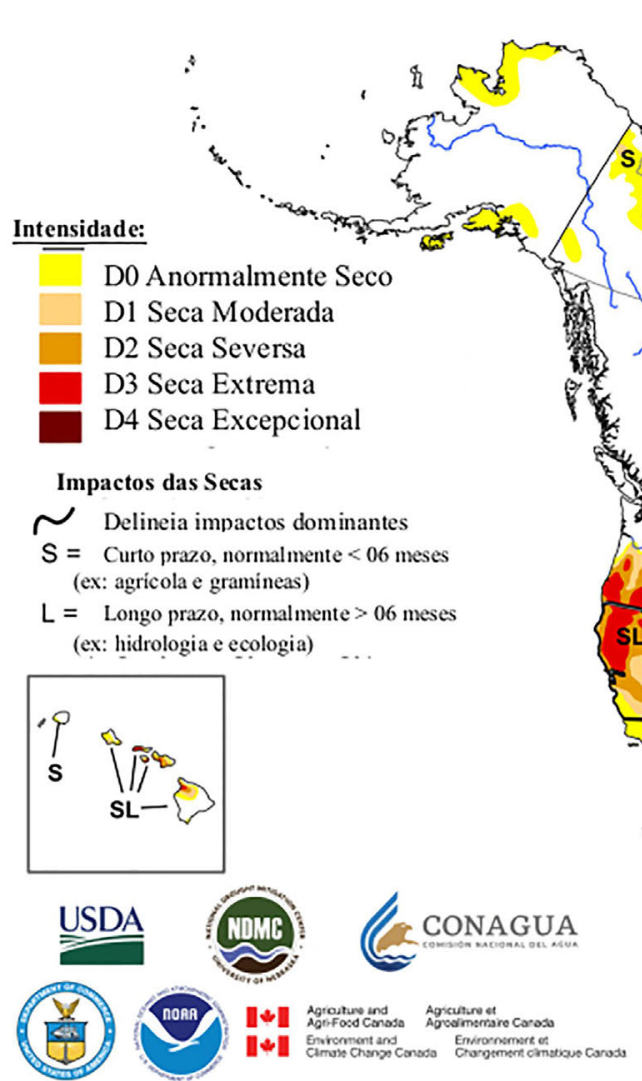

http://www.ncdc.noaa.gov/temp-and-precip/drought/nadm Analistas:

Canadá - Trevor Hadwen Alyssa Klein *

México - Reynaldo Pascual Minerva Lopez. Estados Unidos - Richard Heim ('Responsável por coletar dados de análise e montar o mapa do Monitor).

Figura 3 - Monitor de Secas da América do Norte: 30 de novembro de 2020. Fonte: Adaptado de NOAA (2021). 


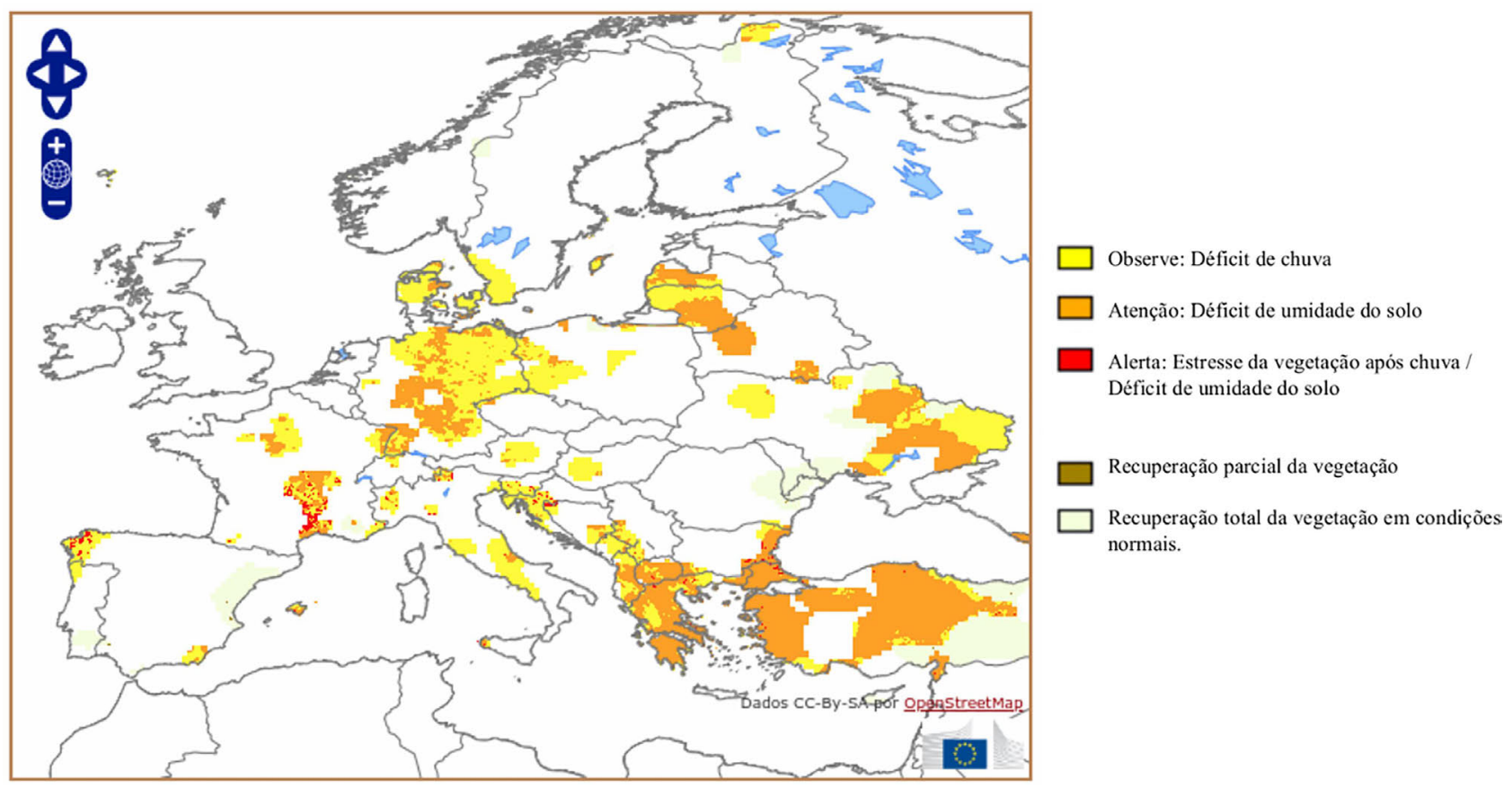

Figura 4 - Mapa atual do EDO: janeiro de 2021 ( $1^{\circ}$ período de dez dias) Fonte: Adaptado do Monitor de Secas da Europa (2021).

individual, sem a combinação de dados e geração de mapas categorizados, o que dificulta a interpretação e traz limitações de uso (Ribeiro Neto 2017; Sheffield et al., 2014).

\subsubsection{Germany Drought Monitor - GDM}

O GDM tem por função fornecer informações diárias atualizadas sobre a seca agrícola e a umidade do solo na Alemanha. Além disso, atua como base decisória para acionar políticas de combate à seca. Os dados utilizados advêm de simulações que aplicam o modelo Hidrológico de Mesoescala (mHM), desenvolvido pela própria instituição (UFZ, 2020; Zink et al., 2016).

Os mapas a seguir (Fig. 5), apresentam o estado de seca do solo de maneira total e superficial e a água disponível para a vegetação. Cada categoria de seca associase a uma cor, quanto mais clara for a cor, menor será o estado de seca em que se encontra a região.

\subsubsection{Monitor de Secas da Índia}

O sistema experimental de monitoramento de secas para a Índia foi desenvolvido pelos pesquisadores Shah e Mishra (2015). Este fornece informações sobre as secas meteorológicas, agrícolas e hidrológicas em tempo real. Para isso, são utilizados os seguintes índices: SPI, SSI e SRI.

\subsubsection{Monitor de Sequía em México - MSM}

O monitoramento das secas no México iniciou em 2002, por meio das atividades do NADM. Porém, em 2014 ele adquiriu caráter nacional, o que lhe permitiu a geração de mapas de secas com escala quinzenal. Sua construção baseia-se nas metodologias aplicadas no USDM e NADM. O produto final é utilizado para disparar ações reativas em eventos de maior intensidade e emitir alerta precoce da seca (CONAGUA, 2019; Arreguín-Cortés et al., 2016).

\subsubsection{Monitor de Secas do Brasil}

No Brasil, a Agência Nacional das Águas e Saneamento Básico (ANA) é a responsável pela organização da Rede Hidromeotológica Nacional (RHN). Atualmente, essa rede conta com 4.641 pontos de monitoramento difundidos pelo país, os quais são divididos em estações que monitoram as características dos rios (vazão, qualidade da água. nível e sedimento) e das chuvas (BIGONHA et al., 2020; ANA, 2020a).

Dentre as inúmeras atribuições, a ANA conta com a Sala de Situação, que se destaca como um sistema de monitoramento e análise da evolução das chuvas, assim como das vazões e níveis dos principais reservatórios, rios e bacias hidrográficas. Esse acompanhamento dos recursos hídricos das regiões permite um melhor monitoramento de eventos de cheias e inundações. Para isso, são gerados boletins diários que tem por finalidade auxiliar os gestores nas tomadas de decisão em caso de eventos extremos no país (Bigonha et al., 2020; ANA, 2020b).

Além disso, a ANA também é responsável por outra importante ferramenta que realiza o monitoramento das secas no país, o Monitor de Secas do Brasil. Este foi criado em 2014, com a finalidade de aliar a compreensão científica e a tecnológica a respeito da seca para alcançar uma abordagem geral sobre as suas condições e caracte- 


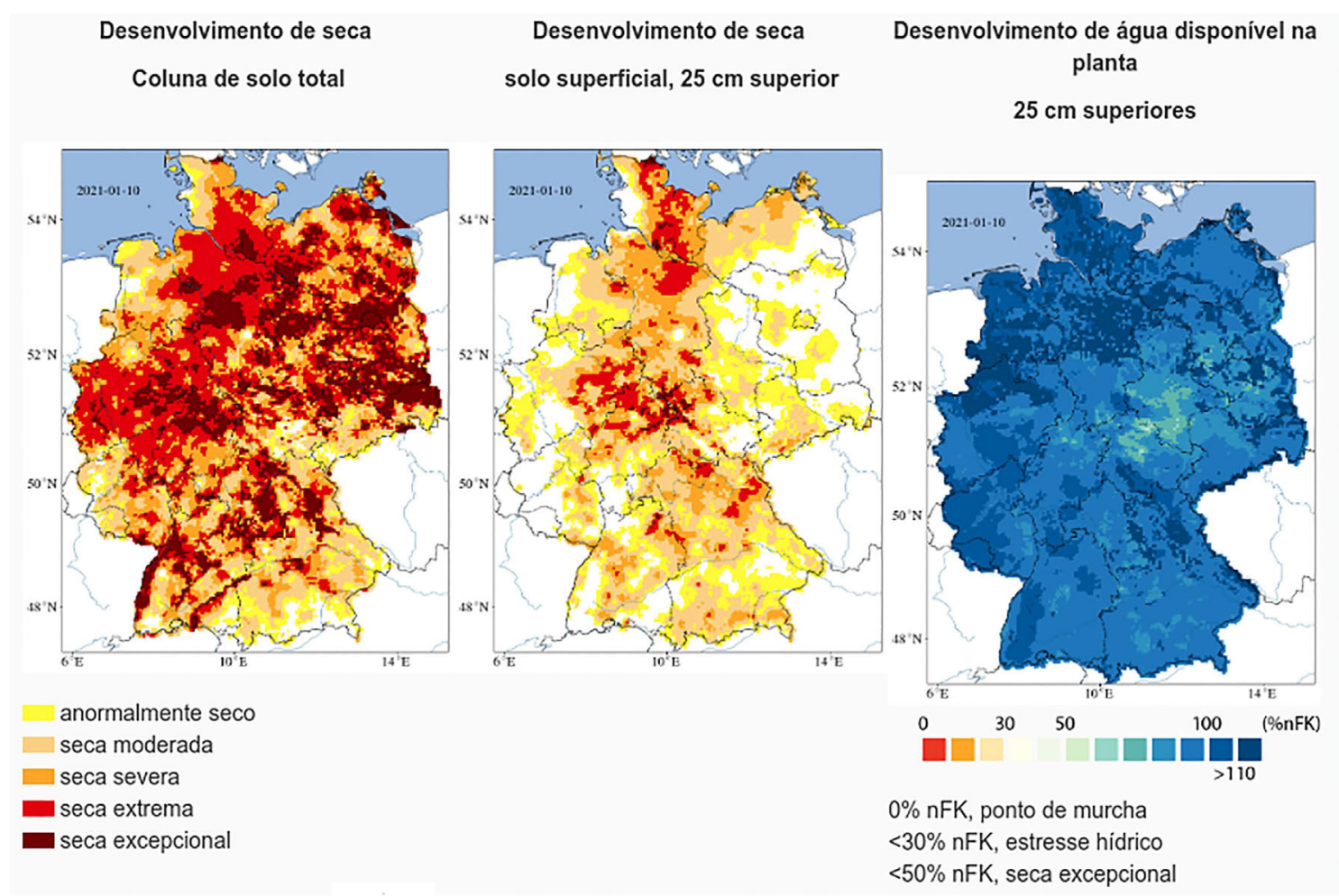

Figura 5 - Monitor de Secas da Alemanha referente ao dia 10/01/2021. Fonte: Adaptado do Monitor de Secas da Alemanha (GDM - 2021).

rísticas. Sua elaboração decorre da compilação dos índices (SPI, SPEI e SDSI) de curto e longo prazo e produtos de apoio (Temperatura Máxima e Média, Precipitação acumulada, Anomalia e Climatologia) que demonstram a evolução da seca na região. Seus resultados são divulgados através de mapas mensais, que facilitam o entendimento das informações disponibilizadas (ANA, 2020b; ANA, 2020c; Martins et al., 2015).

A Fig. 6 apresenta o mapa mensal do Monitor de Secas para o mês de dezembro de 2020, em que é possível perceber a ocorrência de seca em quase toda a área de abrangência do monitor.

\section{Considerações Finais}

Este trabalho buscou apresentar uma revisão dos principais índices de seca e suas aplicações, bem como as metodologias de monitoramento aplicadas ao redor do mundo.

O emprego de sistemas de monitoramento que utilizam de forma individual ou conjunta as informações provenientes dos índices de seca, facilitam a interpretação dos resultados obtidos e a sua transformação em ferramentas e produtos que podem ser aproveitados por instituições e indivíduos de modo geral. Podem atuar como guia de referência para disparar políticas públicas e tomadas de decisões. Além disso, podem fornecer informações importantes para dar suporte na elaboração de planos de con- tingência para melhorar o gerenciamento dos recursos hídricos de uma região vulnerável ao clima. Dessa forma, pode-se haver a adoção ou suspensão de planos de combate aos efeitos da seca nos diversos setores da sociedade.

Porém, incertezas nas informações meteorológicas e hidrológicas podem levar à erros de classificação e caracterização das secas, assim como, à falsas projeções climáticas. Apesar de muitos países já contarem com seus sistemas de monitoramento bem consolidados e efetivos, outras partes do mundo ainda têm carência de informações abrangentes e de ferramentas que possam realizar o acompanhamento e o alerta precoce das secas. Essas deficiências podem ser explicadas pelos seguintes motivos: uso de bancos de dados inadequados (baixa quantidade, abrangência de estações e qualidade dos dados), alta complexidade dos dados ou dos produtos gerados (dificulta o uso dos tomadores de decisão), emprego inapropriado de índices, ausência de indicadores físicos e socioeconômicos, inexistência de metodologias de avaliação da seca e dos seus impactos e falta de tecnologias.

Esses obstáculos podem ser vencidos por meio de soluções coordenadas, onde busca-se aliar o conhecimento técnico e científico. Além disso, existe a necessidade de mudanças, no sentido de adotar uma gestão proativa da seca, que se preocupa em tratar as fragilidades e não somente os sintomas. Para isso, podem ser utilizadas ferramentas eficazes de monitoramento e alerta precoce a níveis federal, estadual e municipal, com foco na obtenção 


\section{Monitor de Secas Dezembro/2020}

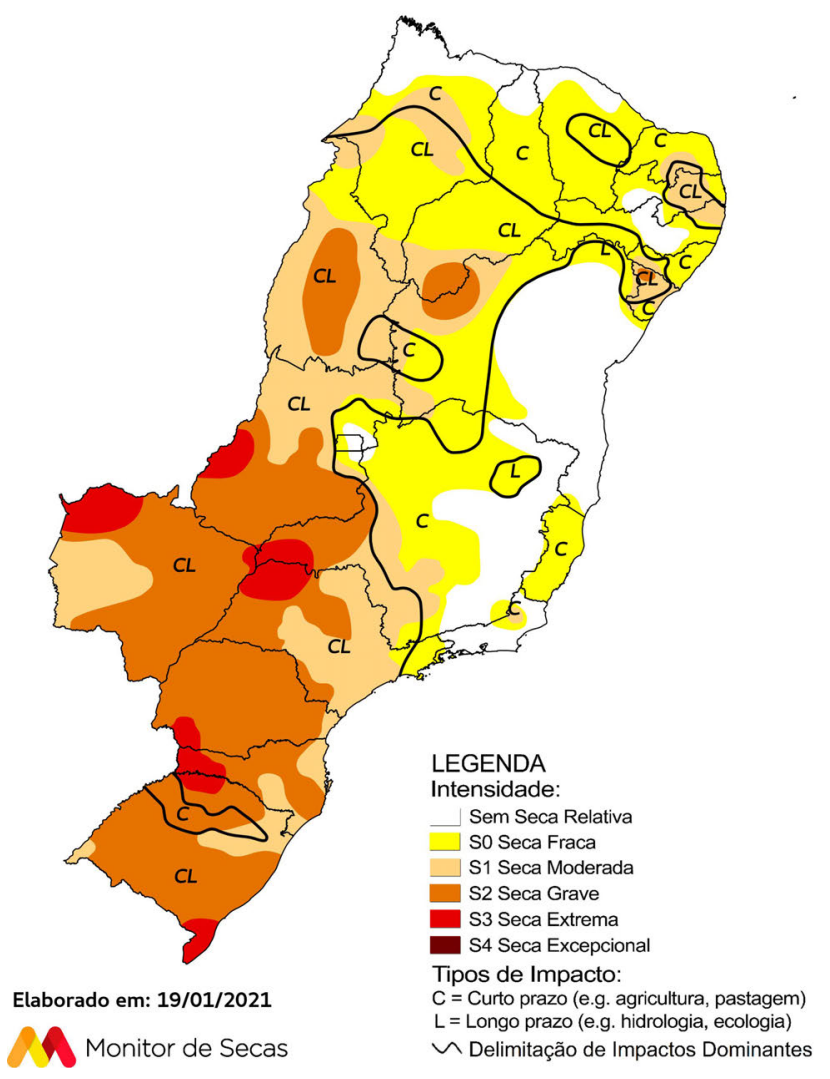

Figura 6 - Monitor de Secas do Brasil (dezembro de 2020). Fonte: Agência Nacional das Águas e Saneamento Básico (ANA) (2020c).

de informações, preparação, elaboração de planos de prevenção e atenuação de impactos. Também pode-se incentivar a interação entre os especialistas e os decisores e apoiar estudos que apresentem como temática o monitoramento, avaliação, previsão e gestão de riscos de secas.

A adoção de políticas proativas, com foco na preparação e no gerenciamento de riscos para as secas, proporciona uma diminuição dos danos causados à economia e dos custos envolvidos na recuperação desses desastres. Vale ressaltar que, essas ações (proativas) trazem melhorias para a gestão dos recursos hídricos, pois elas têm a capacidade de aumentar a adaptação e a resiliência do setor.

\section{Agradecimentos}

Os autores agradecem à Agência Nacional das Águas e Saneamento Básico (ANA), em especial ao Programa Monitor de Secas, por todo suporte para o desenvolvimento dessa pesquisa.

\section{Referências}

ADGER, W.N.; DAW, T.; BROWN, K.; BADJECK, M. Summary for Policymakers. Climate Change 2007: Impacts, Adaptation and Vulnerability, M. L. Parry et al. (eds.). Cambridge: Cambridge University Press, 2007.

ANDRADE, R.P.L.de. Análise das Secas na Bacia do Rio do Peixe Através de Índice Relacionado à Vazão - SRI. Trabalho de Conclusão de Curso, Curso de Engenharia Civil, Centro de Tecnologia, Universidade Federal da Paraíba, João Pessoa, 64 p., 2016.

ARREGUÍN-CORTÉS, F.I.; LÓPEZ-PÉREZ, M.; ORTEGAGAUCIN, D.; IBAÑEZ-HERNÁNDEZ, Ó. La política pública contra la sequía en México: avances, necesidades y perspectivas. Tecnología y Ciencias del Agua, v. 7, n. 5, p. 63-76, 2016.

BIGONHA, M.; LAPPICY, T.; ROMAN, V.; SOUZA, S.A. Ferramenta computacional livre de apoio a Sistemas de Alerta e Monitoramento de eventos hidrometeorológicos críticos. XV Simpósio de Recursos Hídricos do Nordeste. Evento Online, p. 1-10, 2020.

BLAIN, G.C.; PEZZOPANE, J.R.M.; PEZZOPANE, J.E.M.; BONOMO, R. Índice Padronizado de Precipitação aplicado às condições de seca no Estado do Espírito Santo. Revista Brasileira de Engenharia Agrícola e Ambiental, v. 14, n. 10, p. 1067-1073, 2010.

CAMPOS, J.N.B. A gestão das águas e o desenvolvimento do Estado do Ceará: uma perspectiva histórica. T \& C Amazônia, Ano IV, n. 9, 2006.

CARRÃO, H.; RUSSO, S.; SEPULCRE-CANTO, G.; BARBOSA, P. An empirical standardized Soil Moisture Index for agricultural drought assessment from remotely sensed data. International Journal of Applied Earth Observation and Geoinformation, v. 48, n.1, p. 74-84, 2016.

CHEN, L. G.; GOTTSCHALCK, J.; HARTMAN, A.; MISKUS, D.; TINKER, R., et al. Flash Drought Characteristics Based on U.S. Drought Monitor. Atmosphere, v. 10, n. 9, p. 498, 2019.

DOESKEN, N.J.; MCKEE T.B.; KLEIST. J. Development of a Surface Water Supply Index (SWSI) for the Western United States. Climatology Report. Collins: Colorado State University, 1991.

FARAJZADEH, M.; NIKEGHBAL, M.; RAFATI, S.; ADAB, H. Meteorological drought monitoring based on an efficient index, using Geostatistical analyst in Ghare Aghaj watershed. International Conference of Water Crisis, Iran, 2009.

FECHINE, J.A.L. Identificação de secas meteorológicas na região metropolitana de Fortaleza, usando o Índice de Precipitação Padronizada (SPI). Boletim de Geografia, v. 33, n. 2, p. 18, 2015.

FERNANDES, D.S.; HEINEMANN, A.B.; PAZ, R.L.; AMORIM, A.O.; CARDOSO, A.S. Índices Para A Quantificação Das Secas. Santo Antônio de Goiás: Embrapa Arroz e Feijão, 2009.

FERREIRA, L.K.R. Análise Comparativa Do Desempenho De Índices De Seca Aplicados À Região do Alto Jaguaribe Ceará. Dissertação de Mestrado, Curso de Engenharia Civil, Centro de Tecnologia, Universidade Federal do Ceará, 84 p. 2016. 
FERREIRA, L.K.R.; FERREIRA, F.E.F.R.; COELHO, T.L.S.; PINHEIRO, A.I.; FERREIRA, A.L.R. et al. Aplicação de índices de quantificação de secas no Brasil: Revisão exploratória. XII Congresso Nacional De Meio Ambiente de Poços de Caldas, Poços de Caldas, 2015.

GANAPATHI, H. Assessment of drought severity using Standard Precipitation Index in Ahmednagar district, India. Assessment, v. 5, n. 5, p. 1777-1780, 2018.

GANDU, A.W.; SILVA, R.F.; MARTINS, E.S. Drought identification in Cearà state using the Standardized Precipitation Index (SPI). Proceedings of the VI Simpòsio Internacional de Climatologia, Natal, Brazil, p.13-16, Outubro, 2015.

GAREN, D.C. Revised Surface Water Supply Index for the Western United States. Journal Water Resour. Plann. Manage., v. 119, n. 4, p. 437-454, 1993.

GIL, A.C. Como classificar as pesquisas. Como Elaborar Projetos de Pesquisa. São Paulo: Atlas, v. 4, p. 44-45, 2002.

GUTTMAN, B.N. Comparaing the Palmer Drought Index and the Standardized Precipitation Index. Journal of the American Water Resources Association. v. 34, n. 1, p. 113-121, 1998.

HANNAFORD, J.; LLOYD-HUGHES, B.; KEEF, C.; PARRY, S.; PRUDHOMME, C.L. Examining the large-scale spatial coherence of European drought using regional indicators of precipitation and streamflow deficit. Hydrological Processes, v. 25, n. 7, p. 1146-1162, 2011.

HAYES, M.J.; SVOBODA, M.V.; WALL, N.; WIDHALM, M. The Lincoln Declaration on Drought Indices: universal meteorological drought index recommended. Bulletin of the American Meteorological Society, n. 92, v. 4, p. 485488. 2011.

HAYES, M.J.; SVOBODA, M.D.; WARDLOW, B.D.; ANDERSON, M.C.; KOGAN, F. Drought monitoring: Historical and current perspectives. In: Remote Sensing of Drought: Innovative Monitoring Approaches. Boston: CRC Press/ Taylor \& Francis, p. 1-19, 2011.

HAYES, M. J.; SVOBODA M. D.; WILHITE D. A.; VANYARKHO O. V. Monitoring the 1996 drought using the Standardized Precipitation Index. Bulletin of the American Meteorological Society, v. 80, p. 429-438, 1999.

HEIM, R.R.; BREWER, M.J. The Global Drought Monitor Portal: The Foundation for a Global Drought Information System. Earth Interactions, v. 16, n. 15, p. 1-28, 2012.

INOCÊNCIO, T. de M.; RIBEIRO NETO, A.; SOUZA, A.G.S.S. Soil moisture obtained through remote sensing to assess drought events. Revista Brasileira de Engenharia Agrícola e Ambiental, v. 24, n. 9, p. 575-580, 2020.

JANG, S.H.; LEE, J.K.; OH, J.H.; JO, J.W.; CHO, Y. The probabilistic drought forecast based on the ensemble technique using the Korean Surface Water Supply Index. Natural Hazards And Earth System Sciences Discussions, v. 10, n. 10, p.1-51, 19.2017.

JANUZZI, P. de M. Indicadores sociais no Brasil: Conceitos, Fontes de Dados e Aplicações. São Paulo: Alínea, ed. 3, p. 141-141, 2004.

JAGER, A.L.; VOGT, J.V. Analyzing the Combined Drought Indicator (CDI): Demonstration and Analysis of its Evolution during Spring and Summer 2013-2014. Agriculture and Agricultural Science Procedia, v. 4, p. 222-231, 2015.

JOHANN, J.A.; ROCHA, V.J.; DUFT, D.G.; LAMPARELLI, R.A.C. Estimativa de áreas com culturas de verão no Paraná, por meio de imagens multitemporais EVI/Modis. Pesquisa Agropecuária Brasileira, v. 47, n. 9, p. 12951306, 2012.

KEYANTASH, J.A.; DRACUP, J.A. The Quantification of Drought: An Evaluation of Drought Indices. Bulletin of the American Meteorological Society, v. 83, n. 8, p. 11671180, 2002.

KOGAN, F.N. World droughts in the new millennium from AVHRR-based Vegetation Health Indices. EOS, Transaction American Geophysics Union, v. 83, n. 48, p. 557563,2002

LEIVAS, J.F.; ANDRADE, R.G.; VICTORIA, D.D.C.; TORRESAN, F.E.; BOLFE, E.L et al. Monitoramento da seca ocorrida em 2012 no Nordeste Brasileiro a partir dos dados Spot-Vegetation e TRMM. Embrapa Monitoramento por Satélite. Artigo em anais de congresso (ALICE). Simpósio Regional de Geoprocessamento e Sensoriamento Remoto, Aracaju. Embrapa Tabuleiros Costeiros, 2012.

LOPEZ-MORENO, J.I.; VICENTE-SERRANO, S.M.; BEGUERÍA, S.; GARCÍA-RUIZ, J.M.; PORTELA, M.M. et al. Dam effects on droughts magnitude and duration in a transboundary basin: TheLower River Tagus, Spain and Portugal. Water Resour. Res., v. 45, n. 2, p. W02405, 2009.

MACEDO, M.J.H.; GUEDES, R.V.D.S.; SOUSA, F.D.A.S. Monitoramento e intensidade das secas e chuvas na cidade de Campina Grande/PB. Revista Brasileira de Climatologia, v. 8, p. 105-117, 2011.

MAGALHÃES JÚNIOR, A.P. Indicadores ambientais e recursos hídricos: realidades e perspectivas para o Brasil a partir da experiência francesa. Rio de Janeiro: Bertrand Brasil, v. 1, n. 2, p. 688, 2007.

MARTINS, E.S.P.R.; DE NYS, E.; MOLEJÓN, C.; BIAZETO, B.; SILVA, R.F.V. et al. Monitor de Secas do Nordeste, em busca de um novo paradigma para a gestão de secas. Brasília: Banco Mundial, Série Água, v. 10, n. 106302, p. 1-128, 2015.

MARX, A.; ZINK, M.; POMMERENCKE, J.; KUMAR, R.; THOBER, S. et al. The German Drought Monitor. EGU General Assembly Conference Abstracts, Viena, Austria, p. 5625, 2015.

MCKEE, T.B.; DOESKEN, N.J.; KLEIST, J. The Relationship of Drought Frequency and Duration to Time Scales. Paper Presented at 8th Conference on Applied Climatology. American Meteorological Society, v. 7, n. 22, p. 179-183, 1993.

MEDEIROS, G.C.S. de; MAIA, A.G.; MEDEIROS, J.D.F. de. Seca Hidrológica: uma abordagem sob a perspectiva da demanda hídrica. Simpósio de Rcursos Hidrícos do Nordeste, Aracaju: Departamento de Engenharia Ambiental, p. 1-8, 2016.

MEDEIROS, G.C.S. Metodologia de Avaliação da Seca Hidrológica sob a Perspectiva da Demanda Hídrica. Dissertação de Mestrado, Curso de Engenharia Sanitária, Centro de Tecnologia, Universidade Federal do Rio Grande do Norte, 78 p., 2016. 
MENESES, P.R.; ALMEIDA, T. de. Introdução ao processamento de imagens de sensoriamento remoto. Conselho Nacional de Desenvolvimento Científico e Tecnológico, Brasília: UnB, p. 1-266, 2012.

MISHRA, A.K.; SINGH, V.P. A review of drought concepts. Journal of Hydrology, v. 391, n. 1-2, p. 202-216, 2010.

MODARRES, R. Streamflow drought time series forecasting. Stochastic Environmental Research and Risk Assessment, v. 21, n. 3, p. 223-233. 2007.

NALBANTIS, I.; TSAKIRIS, G. Assessment of hydrological drought revisited. Water Resources Management, v. 23, n. 5, p. 881-897, 2008.

NAUMANN, G.; BARBOSA, P.; CARRAO, H.; SINGLETON, A.; VOGT, J. Monitoring Drought Conditions and TheirUncertainties in in Africa Using TRMM Data. American Meteorological Society, Journal of Applied meteorology and Climatology, v. 51, n. 10, p. 1867-1874, 2012.

NEIVERTH, W; CRUSIOL, R.; CARVALHO, J.; FERREIRA, L.; RIO, A. et al. NDVI de estádios fenológicos da soja BRS 284 de crescimento indeterminado em casa de vegetação. In Embrapa Soja-Artigo em anais de congresso (ALICE). In: Jornada Acadêmica da Embrapa Soja, Londrina. Embrapa Soja, Resumos expandidos. Documentos, 339, v. 8, p. 204-209, 2013.

PABLOS, M.; MARTÍNEZ-FERNÁNDEZ, J.; SÁNCHEZ, N.; GONZÁLEZ-ZAMORA, Á. Temporal and spatial comparison of agricultural drought indices from moderate resolution satellite soil moisture data over Northwest Spain. Remote Sensing, v. 9, n. 11, p. 1168, 2017.

PALMER, W.C. Keeping track of crop moisture conditions, nationwide: the Crop Moisture Index. Weatherwise, v. 21, p. 56-161, 1968.

PANU, U.S; SHARMA, T.C. Desafios na pesquisa sobre seca: algumas perspectivas e direções futuras. Journal Hydrol. Sci. v. 47, p. 19-30, 2002.

PATEL, N.R.; CHOPRA, P.; DADHWAL, V.K. Analyzing spatial patterns of meteorological drought using standardized precipitation index. Meteorological Applications: A Journal Of Forecasting, Practical Applications, Training Techniques And Modelling, v. 14, n. 4, p. 329-336, 2007.

PESSINI, P.B. Estudo dos Eventos de Seca Meteorológica na Região Sul do Brasil. Trabalho de Conclusão de Curso, Universidade Federal de Santa Catarina, Centro Tecnológico, Graduação em Engenharia Sanitária e Ambiental, Florianópolis, 87 p. 2017.

PONTES FILHO, J.D.; PORTELA, M.M.; STUDART, T.M. de C.; SOUZA FILHO, F. de A. A continuous drought probability monitoring system, CDPMS, based on copulas. Water, v. 11, n. 9, p. 1925, 2019.

RHEE, J.; IM, J.; CARBONE, G.J. Monitoring agricultural drought for arid and humid regions using multi-sensor remote sensing data. Remote Sensing of Environment, v. 114, n. 12, p. 2875-2887, 2010.

RIBEIRO NETO, G.G. Monitoramento e Caracterização de Secas da América do Sul com Sensoriamento Remoto. Dissertação de Mestrado, Curso de Recursos Hídricos e Saneamento Ambiental, Programa de Pós-Graduação em Recursos Hídricos e Saneamento Ambiental, Universidade Federal do Rio Grande do Sul, Porto Alegre, 76 p., 2017.
ROSA, R.G.T.D. Índices de Seca: Aplicação ao Continente Português. Dissertação de Mestrado, Curso de Engenharia Agrônoma, Instituto Superior de Agronomia, Universidade Técnica de Lisboa, Lisboa, 81 p., 2011.

ROUSE J.W.; HAAS JUNIOR, R.H.; SCHELL J.A.; DEERING, D.W. Monitoring vegetation systems in the Great Plains with ERTS. Third ERTS Symposium, NASA Special Publication, v. 351, n. 1974, p. 309-317, 1973.

ROSSATO, L.; ALVALÁ, R.C. dos S.; MARENGO, J.A.; ZERI, M.; CUNHA, A.P.M. do A. et al. Impact of soil moisture on crop yields over Brazilian semiarid. Frontiers of Environmental Science \& Engineering, v. 5, n. 15, p.116, 2017.

SALESKA, S.R.; DIDAN, K.; HUETE, A.R.; da ROCHA, H.R. Amazon forests green-up during 2005 drought. Science, v. 318, n. 5850, p. 612-612, 2007.

SAMANTA, A.; GANGULY, S.; HASHIMOTO, H.; DEVADIGA, S.; VERMOTE, E. et al. Amazon forests did not green-up during the 2005 drought. Geophysical Research Letters, v. 37, n. 5, 2010.

SANTOS, J.F.; PORTELA, M.M. Caracterização de Secas em Bacias Hidrográficas de Portugal Continental: Aplicação do Índice de Precipitação Padronizada, SPI, a Séries de Precipitação e de Escoamento. Lisboa: Associação Portuguesa dos Recursos Hídricos, 2010.

SANTOS, K.M.S. Avaliação da Eficiência do Monitor de Secas para Definição de Secas em Sergipe. Dissertação de Mestrado em Engenharia Civil, Universidade Federal de Sergipe, São Cristóvão, 147 p. 2020.

SEILER R.A.; HAYES M.; BRESSAN L. Using the Standartized Precipitation Index for flood risk monitoring. International Journal of Climatology: A Journal of the Royal Meteorological Society, v. 22, n. 11, p. 1365-1376, 2002.

SHAFER, B.A.; DEZMAN, L.E. Development of a Surface Water Supply Index (SWSI) to assess the severity of drought conditions in snowpack runoff areas. In: Proceedings of the 50th Annual Western Snow Conference. Fort Collins: Colorado State University, p. 164-75, 1982.

SHAH, R.D.; MISHRA, V. Development of an Experimental Near-Real-Time Drought Monitor for India. Journal of Hydrometeorology, v. 16, n. 1, p. 327-345, 2015.

SICHE, R.; AGOSTINHO, F.; ORTEGA, E.; ROMEIRO, A. Índices versus indicadores: precisões conceituais na discussão da Sustentabilidade de países. Revista Ambiente \& Sociedade, v. 10, n. 2, p. 137-148, jul-dez, 2007.

SILVA, A.; SANTO, F.; PIRES, V. A Seca em Portugal: Prevenção, Monitorização e Mitigação. Lisboa: Fundação Calouste. Gulbenkian, 2005.

SHEFFIELD, J.; WOOD, E.F.; CHANEY, N.; GUAN, K.; SADRI, S.; et al. A drought monitoring and forecasting system for sub-Sahara African water resources and food security. Bulletin of the American Meteorological Society, v. 95, n. 6, p. 861-882, 2014.

SILVA, D.F da.; LIMA, M.J.S.; SOUZA NETO, P.F.; GOMES, H.B.; SILVA, F.D.S. et al. Caracterização de eventos extremos e de suas causas climáticas com base no Índice Padronizado de Precipitação Para o Leste do Nordeste. Revista Brasileira de Geografia Física, v. 13, n. 2, p. 449-464, 2020. 
SIVAKUMAR, M.V.K.; MOTHA, R.P.; WILHITE, D.A.; WOOD, D.A. Agricultural drought indices: Proceedings of an expert meeting, Murcia, Spain, 2-4 June 2010. World Meteorological Organization Tech. Document AGM-11, WMO/TD-1572, WAOB-2011, p. 220, Eds., 2011a.

SIVAKUMAR, M.V.K.; MOTHA, R.P.; WILHITE, D.A.; QU, J.J. Towards a compendium on national drought policy: Proceedings of an Expert Meeting on the Preparation of a Compendium on National Drought Policy. World Meteorological Organization Rep. AGM-12, WAOB-2011, p. 135, Eds., 2011b.

SILVEIRA JUNIOR, C; FERREIRA JÚNIOR L.G.; SILVA, B.B. Characteristics and challenges of NDVI generation to Brazil from Meteosat-10 geostationary orbit satellite data. Revista Brasileira de Geografia Física, v. 12, n. 3, p. 1142-1155, 2019.

SOBRAL, A.; FREITAS, C.M. de; PEDROSO, M. de M.; GURGEL, H. Definições básicas: Dado, Indicador e Índice. Saúde Ambiental. Guia básico para construção de Biodicadores. Ministério da Saúde. Secretaria de Vigilância em Saúde. Departamento de Vigilância em Saúde Ambiental e Saúde do Trabalhador. Saúde Ambiental: Guia Básico para Construção de indicadores. Brasília: Ministério da Saúde (Série B. Textos Básicos de Saúde), p. 25-52, 2011.

SOUZA, A.G.S.S.; RIBEIRO NETO, A.; ROSSATO, L.; ALVALÁ, R.C.S.; SOUZA, L.L. Use of SMOS L3 Soil Moisture Data: Validation and drought assessment for Pernambuco state, Northeast Brazil. Remote Sensing, v.10, n. 8, p. 1314, 2018.

SOLON, A.O.; CAMPOS, J.N.B.; STUDART, T.M.A.C. Estimativa dos valores esperados para durações máximas de secas hidrológicas no açude Castanhão - CE. Simpósio Brasileiro de Recursos Hídricos, Aracaju. Anais. Aracaju: ABRH, v. 14, 2001.

SOUSA JUNIOR, M.F.de; ULIANA, E.M.; CARVALHO, M.A.C.C.de; MENDES, M.A.D.S.A.; LISBOA, L. Monitoramento de seca meteorológica com dados TRMM para uma região produtora de grãos do Brasil. Revista Ibero-Americana de Ciências Ambientais, v. 12, n. 2, 2021.

SVOBODA, M.; FUCHS, B. Handbook of Drought Indicators and Indices Integrated Drought Management Programme (IDMP). World Meteorological Organization (WMO) and Global Water Partnership (GWP), Integrated Drought Management Programme (IDMP), Integrated Drought Management Tools and Guidelines Series 2. Geneva. 2016.

VALIPOUR, M. Use of Surface Water Supply Index to assessing of water resources management in Colorado and Oregon, US. Advances In Agriculture, Sciences And Engineering Research, Nigéria, v. 3, n. 2, p. 631-640, fev, 2013.

VAN LOON, A.F. Hydrological drought explained. Wiley Interdisciplinary Reviews: Water. Birmingham, UK, v. 2, n. 4, p. 359- 392. jul./ago. 2015.

VICENTE-SERRANO, S.M. Differences in spatial patterns of drought on different time scales: ananalysis of the Iberian Peninsula. Water Resources Management, v. 20, n. 1, p. 37-60. 2006.

YAN, N.; WU, B.; CHANG, S.; BAO, X. Evaluation of TRMM Precipitation Product for Meteorological Drought Monitoring in Hai Basin. 35th International Symposium on
Remote Sensing of Environment (ISRSE35), IOP Conference Series: Earth and Environmental Science. IOP Publishing, p. 012093, 2014. doi:10.1088/1755-1315/17/1/ 012093. 2014.

YIHDEGO, Y.; VAHEDDOOST, B.; AL-WESHA, R.A. Drought indices and indicators revisited. Arabian Journal of Geosciences, v. 12, n. 3, p. 69, 2019.

WILHITE, D.A. National Drought Management Policy Guidelines: A Template for Action. Geneva: World Meteorological Organization, 2014.

WILHITE, D.A.; M. BUCHANAN-SMITH, M. Drought as hazard: Understanding the natural and social context. Drought and Water Crises: Science, Technology, and Management Issues. Boston: Taylor \& Francis Group, p. 3-29, 2005 .

WU, H.; SVODOBA, M.D.; HAYES, M.J.; WILHITE, D.A.; WE, F. Appropriate application of the Standardized Precipitation Index in arid locations and dry seasons. International Journal of Climatology, v. 27, n. 1, p. 65-79, 2007.

ZARCH, M. A.A.; SIVAKUMAR, B.; SHARMA, A. Droughts in a warming climate: a global assessment of Standardized Precipitation Index (SPI) and Reconnaissance Drought index (RDI). Journal of Hydrology, v. 526, p.183-195, 2015.

ZINK, M.; SAMANIEGO, L.; KUMAR, R.; THOBER, S.; MAI, J. et al, A. The German drought monitor. Environmental Research Letters, v. 11, n. 7, p. 074002, 2016.

\section{Endereços de Internet}

AFDM, African Flood and Drought Monitor. 2021. Disponível em: https://iciwarm.info/african-flood-anddrought-monitor-training-in-east-africa/. Acesso em: 20 jan. 20201.

ANA, Agência Nacional das Águas e Saneamento Básico. Portal HidroWeb da ANA. 2020a. Disponível em: http:// www.snirh.gov.br/hidroweb/publico/apresentacao.jsf. Acesso em: 05 abr. 2021.

ANA, Agência Nacional das Águas e Saneamento Básico. Portal da Sala de Situação da ANA. 2020b. Disponível em: https://www.ana.gov.br/sala-de-situacao. Acesso em: 05 abr. 2021.

ANA, Agência Nacional das Águas e Saneamento Básico. Monitor de Secas do Brasil. 2020c. Disponível em: http:// monitordesecas.ana.gov.br/mapa?mes=11\&ano=2020. Acesso em: 10 jan. 2021.

CONAGUA, Comisíon Nacional del Agua. Monitor de Sequía en México. 2019. Disponível em: https://smn.conagua.gob. $\mathrm{mx} /$ es/climatologia/monitor-de-sequia/monitor-de-sequiaen-mexico. Acesso: 10 jan. 2021.

EDO, European Drought Monitor. 2020. Disponível em: https://edo.jrc.ec.europa.eu/edov2/php/index.php?id=1052. Acesso: 10 jan. 2021.

GDM, Germany Drought Monitor. 2021. Disponível em: https://www.ufz.de/index.php?en=37937. Acesso em: 10 jan. 2021.

LAFDM, Latin America Flood and Drought Monitor. 2021. Disponível em: https://www.cazalac.org/mwar_lac/index. php?id=60. Acesso em 15 jan. 2021. 
Monitor de Secas da Índia, Sistema de Monitoramento da Seca. 2021. Disponível em: http://dms.iwmi.org/. Acesso em: 22 jan. 2021.

MSM, Monitor de Secas do México. 2021. Disponível em: https://smn.conagua.gob.mx/es/climatologia/monitor-desequia/monitor-de-sequia-en-mexico Acesso em: 25 jan. 2021.

NADM, North American Drought Monitor. 2021. Disponível em: https://www.ncdc.noaa.gov/temp-and-precip/drought/ nadm/maps. Acesso em: 10 jan. 2021.

NIDIS, National Integrated Drought Information System. Crop Moisture Index (CMI). Drought.gov. Disponível em: https://www.drought.gov/data-maps-tools/crop-moistureindex-cmi. Acesso em: 12 abril. 2021.
NOAA, National Oceanic and Atmospheric Administration National Centers for Environmental Information. North American Drought Monitor. 2020. Disponível em: https://www.ncdc.noaa.gov/temp-and-precip/drought/ nadm/maps. Acesso em: 02 dez. 2020.

USDM, U.S. DROUGHT MONITOR. United States Drought Monitor. 2021. Disponível em: https://droughtmonitor.unl. edu/Maps/MapArchive.aspx. Acesso em: 10 jan. 2021.

License information: This is an open-access article distributed under the terms of the Creative Commons Attribution License (type CC-BY), which permits unrestricted use, distribution and reproduction in any medium, provided the original article is properly cited. 